\title{
Good WIL hunting: Building capacity for curriculum re-design
}

\author{
Karen Young ${ }^{1}$, Stuart Palmer ${ }^{2}$ and Malcolm Campbell ${ }^{2}$ \\ k.young@deakin.edu.au; stuart.palmer@deakin.edu.au; malcolm.campbell@deakin.edu.au
}

${ }^{1}$ Deakin University, Melbourne, Burwood Campus, Australia

${ }^{2}$ Deakin University, Waurn Ponds, Australia

\begin{abstract}
In response to government, industry, student and central University calls for initiatives to enhance graduate employability as a means for improved employment outcomes, a faculty within an Australian university formulated a five-year Work Integrated Learning (WIL) strategy (2015-2019). The Faculty goal was to re-new, develop, implement and evaluate scalable and sustainable intentional WIL-focused authentic curricula across every undergraduate Science, Technology, Engineering and Mathematics (STEM) course by the end of 2019. A 'WIL Leadership Framework' underpinned the whole-of-course team approach. This paper reports on the change-management processes and behaviours necessary to effect change from the bottom-up. Fostering academic staff capacity to build course-appropriate WIL curriculum has been slow and subtle and yet significant refinements to intentional and embedded WIL curriculum have occurred through a series of grounded research studies and curriculum renewal projects. WIL champions (the innovators), earmarked as change agents for enabling scalable curriculum transformation and renewal, were 'hunted-out' and nurtured. Their role was to influence teachers to enact context-specific and discipline-based WIL experiences into the curriculum. The main research findings to date reveal that STEM-specific WIL frameworks, concepts and assessment examples, presented as scholarly curriculum choices by WIL experts, and then actively and collegially discussed amongst the WIL champions and WIL early adopters, has been the most effective process to date for developing a WIL centred curriculum. The paper concludes by addressing the current operational goals predicated to have an impact on graduate employment for the Faculty.
\end{abstract}

Keywords: Work Integrated Learning (WIL), leadership, curriculum, employability, capacity building, authentic assessments

\section{Context}

The call for educational strategies to equip graduates for the jobs and skills of the future is a key message relating to the future of the Australian economy (Universities Australia, Australian Chamber of Commerce Industry, Australian Industry Group, Business Council of Australia, \& Australian Collaborative Education Network, 2015). High level Australian Government policy requires the Higher Education (HE) sector to prepare students to transition effectively into these unknown jobs with skills of the future (Oliver, 2015). Universities are being encouraged to think about the changing landscapes of future employment for graduates and the implications for HE that might make students more likely to find and create meaningful paid 
and unpaid work that benefits themselves, the workforce, the community and the economy (Oliver, 2015, p. 63). Work-related, contextualised, authentic learning and assessment activities that enable students to apply their course knowledge and graduate capabilities, preferably at the same time, are found to significantly aid the development of employability skills (Billet, 2001; Eraut \& Hirsh, 2007; Patrick et al., 2008; Yorke, 2006). What is common now is a range of university strategies explicitly marking Work Integrated Learning (WIL) programs as a primary driver for achieving the goal of evidencing the employability outcomes for university courses and for developing work-ready graduates. WIL is used as the curriculum strategy of preference for producing graduates who are 'employment ready' (Smith, 2016, p. 345).

Increasingly, WIL and career education activities are earmarked as the silver bullet for improving the employment of graduates; but how does a course endeavour to make a positive impact on employment outcomes? The Faculty in which this study took place is setting out to test the hypothesis that curricula focused on providing intentional, scaffolded and applied learning, contextualised to relevant and up to date industry benchmarked skills and knowledge typical in STEM settings, will enhance employment for graduates in the sector. Furthermore, WIL curricula that clearly signposts the transferable nature of employability skills, alongside a shift away from learning focused on knowledge-acquisition (common in STEM), will enhance employment for graduates.

Since 2015 and continuing into 2017, a series of parallel projects and studies have been conducted to provide a scholarly approach to improving WIL curricula (Campbell, 2016; HainsWesson \& Young, 2017; Palmer, Tolson, Young, \& Campbell, 2015; Tolson \& Young, 2016; Willems, Young, Cardilini, \& Teychenne, 2016; Young, Cardilini, Willems, \& Teychenne, 2016; Young, Palmer, Tolson, \& Campbell, 2016). This study proposes that the most salient means for developing employability skills within a whole-of-course WIL curriculum is through a change management approach. The focus is on preparing and supporting teams of academics, within selected courses, via faculty-wide grounded WIL-oriented research projects, to shift understandings and behaviours towards embedded WIL curriculum. By building the capacity of academics in this space, some will become better equipped in developing and implementing discipline-based WIL curriculum, and others may even assume the informal role of WIL champion - both of which are critical for driving enhanced curriculum. This tactic took shape as the best scalable and sustainable approach for ongoing Faculty-wide change. The approach supports the research findings of similar employability studies that suggest that academics are instrumental in the enactment of HE policies to enable curriculum change (Sin \& Amaral, 2017).

This paper details the first phase of the Faculty approach for developing and improving curricula. A tactical sequence of events saw traction in the mobilisation of capacity building amongst the undergraduate course teams within the Faculty. The completion of the Universitywide curriculum enhancement, review of course learning outcomes and the alignment to University graduate learning outcomes made an impact on the Faculty approach to addressing graduate outcomes through enhanced WIL curricula. First, the Faculty established a WIL Team to drive the strategy for the enhancement of graduate employability outcomes, modelled on the key principles of the WIL Leadership Framework (Patrick et al., 2014). The WIL Team was accountable for 'Shaping the WIL vision' and 'Fostering WIL engagement, expertise and student learning'. The intention responds to suggestions that proper preparation and support of academic staff for WIL is, in practice, still sometimes missing (Abeysekera, 2006). The Faculty favoured the formal leadership initiative as best practice for enabling long-term design and delivery of embedded whole-of-course industry-oriented curricula.

The Faculty practice of 'good WIL hunting' subsequently inspired the title of this paper. In fact, the methodology of the WIL Leadership Project (Patrick et al., 2014), which actively sought WIL leaders in specific discipline areas in universities and employer organisations to capture and showcase WIL expertise, provided a prototype for enlivening our WIL Curriculum Renewal Strategy. From the beginning of 2015, the Faculty-based WIL team functioned as an internal 
change management group, dedicated to providing expert guidance on all WIL matters, slowly developing the capacity of WIL practitioners to become the growing group of WIL champions within the Faculty. Then, in 2016, the Faculty was included as one of the six Australian Council of Deans of Science (ACDS) Lighthouse projects lead by Johnson (2016), which saw the WIL team continue to drive the process of building academic capacity of course teams. In 201718, a Faculty WIL on Campus Project drives academics to reimagine, shift and then measure the level of enhanced proximity and authenticity of assessments to meet industry requirements of job-ready-plus graduates.

Perhaps the best way to explain the approach taken by the Faculty to enable WIL-lens curricula re-design is to illustrate the narrative used by the WIL experts in their goal to build awareness about the possibility of attempting small changes to 'class-room' and assessment activities. The main thrust of the rhetoric is that teaching teams should maintain their good practice in effective transferral of discipline-based content, but in addition, layer this with explicit pedagogy that intentionally focuses on contextualised inquiry enacted as the authentic process of the scientist. At the centre are discussions around how to mimic real-world scenarios of science in action, in the classroom. A WIL-focused curriculum change across a course is encouraged to allow incremental development of learning, however, we leniently discourage thinking about scaffolding as theory to practice and encourage activities that simultaneously require the active learning of theory with practice.

For example, first year practical lab classes are suggested as ideal learning spaces and scenarios for including the context of scientific skill development to an array of real-world applications, underpinned by reflective practice. Second year practicals, delivered as half-day labs and designed to build and measure the professional capacity of science students (as opposed to assessing recipe-based and controlled experiment outcomes), with reflective practice, provide a deeper understanding of how to work in a scientific team with wicked problems and work place setting variables. This learning is good practice for preparing students for short-term lab-based placements in industry. Both learning activities would prepare students in their final year of study for industry-informed capstone projects. All should involve active and applied theory-practice reflective learning, (i.e. assessments with reflective practice learning outcomes), to intentionally develop and evidence employability skills (i.e. focus on autonomy with collaboration for accountability and contribution to a research team), to improve the possible varied and multiple professional identities of our graduates. Re-telling the story of how current discipline-based good practice can be enhanced with simple ideas, as the starting point for considering step-change, was the narrative path chosen to patiently drive improved employability outcomes.

Two key components relating to capacity building played out during the curriculum renewal projects: improved shared understanding of the Faculty WIL Strategy and Definition; and the need for a WIL-focused framework for imagining curricula re-design. The first explores the key mechanisms for mobilising the foundations of the WIL curriculum change via Faculty-centric definitions and practices of WIL. This had an impact from the Faculty Executive Leadership Group through to the course-team academics. The second reviews the curriculum models prioritised, adopted and then adapted as tools for the design and delivery of a Faculty-centric approach to WIL curricula.

\section{Review of literature}

The discourse in STEM around developing work-ready graduates tends to suggest that graduates have acceptable entry-level discipline knowledge and skills, however, it is the transferable contexts to which those knowledge bases and skill sets are applied, that need to be addressed. In STEM, Henderson, Beach and Finkelstein (2011) discuss how educational policy makers call for fundamental change in the teaching of STEM (p. 953), so that students are ready for the future complex workforces. A WIL-lens STEM study by Edwards, Perkins, Pearce and Hong (2015) suggests that graduates generally have sufficient knowledge and 
skills to function at an entry level in the field, although they further clarify that to progress, students need the self-awareness to recognise their strengths, and an interest in learning and strategies to assist them to do so (p. 43).

The Mapping Higher Education 2016 report (Norton \& Cakitaki, 2016) presents statistics on Australian HE in general, and provides a specific analysis of STEM student outcomes. The report notes that employment outcomes for science graduates were particularly difficult - only 51 per cent of science graduates looking for work had found it four months after completing their studies - 17 per cent lower than the average for all graduates. Science graduates who are successful in finding work are less likely to say that their work is related to their studies 53 per cent for science graduates, compared to 73 per cent for all graduates. Further out from graduation, employment prospects for science graduates improve, but such employment is often outside of science. The underlying message to the course teams in the Faculty had to be clear if capacity building was going to be productive - current graduate employment outcomes needed to be improved, and the best solution at hand for academics was going to be via a course-wide step change approach to WIL-focused curricula.

\section{Methodology}

To date, approximately 60 Faculty staff have participated in the projects related to this study: comprising six WIL experts in the Faculty-based WIL team; Course Directors and Course Team members belonging to the projects; and selected WIL champions from across the Schools. The projects were configured as research projects to provide grounded research for investigating change-management processes and behaviours. The development and subsequent discussions with Course Teams of adapted WIL curriculum frameworks was a further strategy for effecting change. Support for the projects from the Heads of the School was critical so that relevant and sustainable WIL curricula could cross-fertilise a number of programs in the Faculty. As part of the formal projects, ethics approval was obtained so that participants could take part in a series of online surveys. One survey, as part of the WIL Lighthouse project is complete, and subsequent surveys relating to WIL understandings are still underway.

To mobilise academic capacity to renew curricula, a fit-for-purpose rigorous context-specific curriculum development framework was essential. Three separate employability frameworks were selected:

1). The Core Skills for Work Framework (CSfW) developed by the Department of Education and Training (2016);

2). An Expanded Authenticity and Proximity Framework (EAP) by Kaider, Hains-Wesson \& Young (2017); and

3). An Industry-oriented course model (referred to in this paper as IO) developed by Edwards et al. (2015).

While each was somewhat useful for catalysing the review of WIL curricula, it became clear that specific elements of each framework would be of greater benefit if re-imagined and integrated into one Faculty-centric WIL framework.

The CSfW provided the overarching schema for segmenting curricula needed to enhance jobreadiness from an industry/employer perspective. The essential elements of the CSfW are three work-readiness domains: 'navigating the world of work'; 'interacting with others'; and 'getting the work done' (Department of Education and Training, 2016). The framework was most useful as a 3-tier approach at the course level for planning placement-based WIL learning. What was missing in the CSfW was a curriculum plan for on-campus WIL activity, and furthermore, the scaffolding of authentic and proximal assessment.

The EAP (see Figure 1 below), a familiar framework and tested tool at the University in which this study took place, was a natural choice for adaptation from existing WIL assessment 
frameworks and typologies (Bosco \& Ferns, 2014; Oliver, 2015; Rowe, Winchester-Seeto, \& Mackaway, 2012) for mapping WIL assessments types (Kaider et al., 2017). The 'people' in the proximity axis highlighted the need for, and the value of, practitioner contributions to enable on-campus and WIL-placement curricula. The expanded framework provided more accurate pinpointing and plotting of assessment activities needed for a scalable approach to WIL in the Faculty. The significance of this framework to the capacity building was as a visual tool for revealing to a course team, the hot spots (and gaps) of WIL assessments occurring within the course.

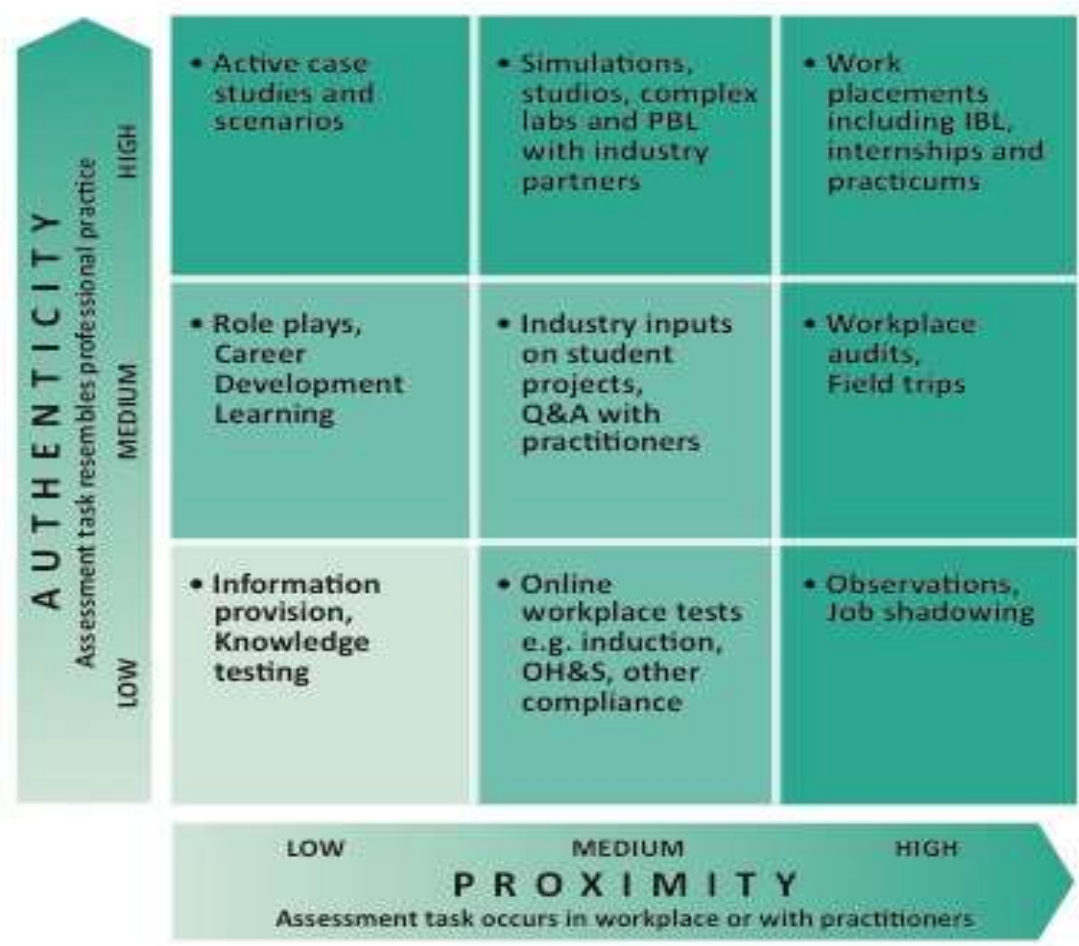

Figure 1: Expanded Authenticity-Proximity (EAP) Framework (Kaider, Hains-Wesson \& Young, 2017)

Narrowing the scope to a STEM approach to WIL proved useful. The study by Edwards et al. (2015) was fundamental for conceptualising the way in which an entire course could be refocused to cater for industry-orientations to, and for, on-campus WIL approaches. The research clearly articulated that WIL practice may be real or simulated and can occur in the workplace, at the university, online, face-to-face or any combination of these but that curriculum has to be about developing practical skills in-context (2015, p.6). The IO model provided a built-in schematic for nine types of learning experiences:

1. Guest lecturers, networking events and field;

2. Explicit units in 'skills for this field' including problem solving, communication;

3. Industry-inspired problems;

4. Simulated work environments;

5. Industry based projects including placement and/or team projects;

6. Units on 'how to get a job in the field' based on applying for placements etc.;

7. Focus on what it means to work in the field;

8. Contextualised learning from the start - learning theory through real problems;

9. Industry input into design and evaluation (Edwards et al., 2015). 
The significance of this model for academics within the Faculty was that it enabled conversations to move beyond placement-based WIL to embedded, whole-of-course WIL. Offcampus one-on-one placement models are resource intensive and are therefore not scalable if inclusivity for all students is sought (Orrell, 2011; Poppins \& Singh, 2005). The provision of alternatives to work placements is necessary. Abeysekera (2006) noted that the success of WIL in the curriculum is influenced by how embedded it is, referring to WIL becoming part of the 'hidden curriculum', becoming part of, ...the norms, values and belief systems embedded in the curriculum (p. 11). As useful as Edward's 10 model was, it lacked much needed exemplars to enliven re-imagined WIL assessments at the coalface.

We pursued an action-learning scholarly project aimed at integrating and customising a curriculum framework to incorporate and integrate the WIL learning activities best suited to STEM pedagogies and learning outcomes (see Figure 4 for the full version of the framework). The following three adaptations occurred concurrently during the review and integration process. First, expanded definitions of what authentic and proximal learning means within the Faculty-context was developed (see Figure 2 below).

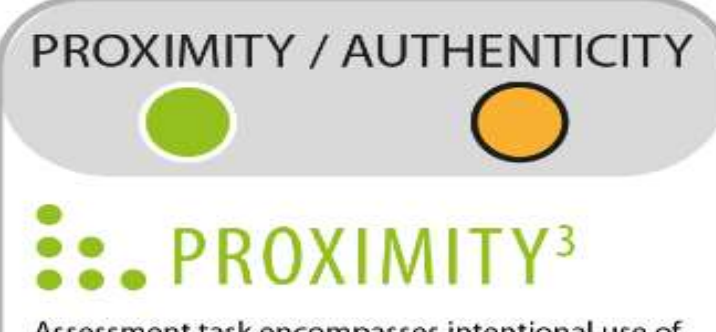

Assessment task encompasses intentional use of practitioners and/or workplaces, on and off campus for in situ learning. High proximity tasks are those which score 3 green dots.

ONE DOT $\odot$ for each of:

Place: Tasks undertaken in a workplace.

People: 'Working to learn' tasks are set and guided by an industry practitioner

Performance: Output is evaluated (assessed) by an industry practitioner

\section{。 \\ $\circ \circ$ $\therefore$ ○ AUTHENTICITY}

Assessment task intentionally resembles tasks undertaken at 'work'. High authenticity tasks are those which score 3 yellow dots.

ONE DOT $\bigcirc$ for each of:

Application: Use knowledge and skills to propose real-world solutions.

Aim: Taskprocess \& output delivers to organisational standards appropriate to the brief.

Autonomy: Evidence (through reflective practice) on the process of learning to collaborate to professional standards.

\section{Figure 2: Defining Authenticity and Proximity}

Second, these definitions formed a $3 \times 2$ criteria system to unpack the three elements of each of authentic and proximal assessment. By way of example, for an assessment task to achieve a 'dot' for the 'aim' section in the authenticity element, it must intentionally contribute to the host organisational goal(s). Third, the addition of exemplars (see Figure 3 below) is an obvious inclusion, but when layered with the dots system, it has perhaps been one of the most effective 
means to date for enabling unit chairs and course directors to re-imagine their assessments. The fit-for-purpose WIL Convergence Curriculum Framework provides an invaluable scholarly resource to support course teams in their discipline-specific WIL learning activity choices.

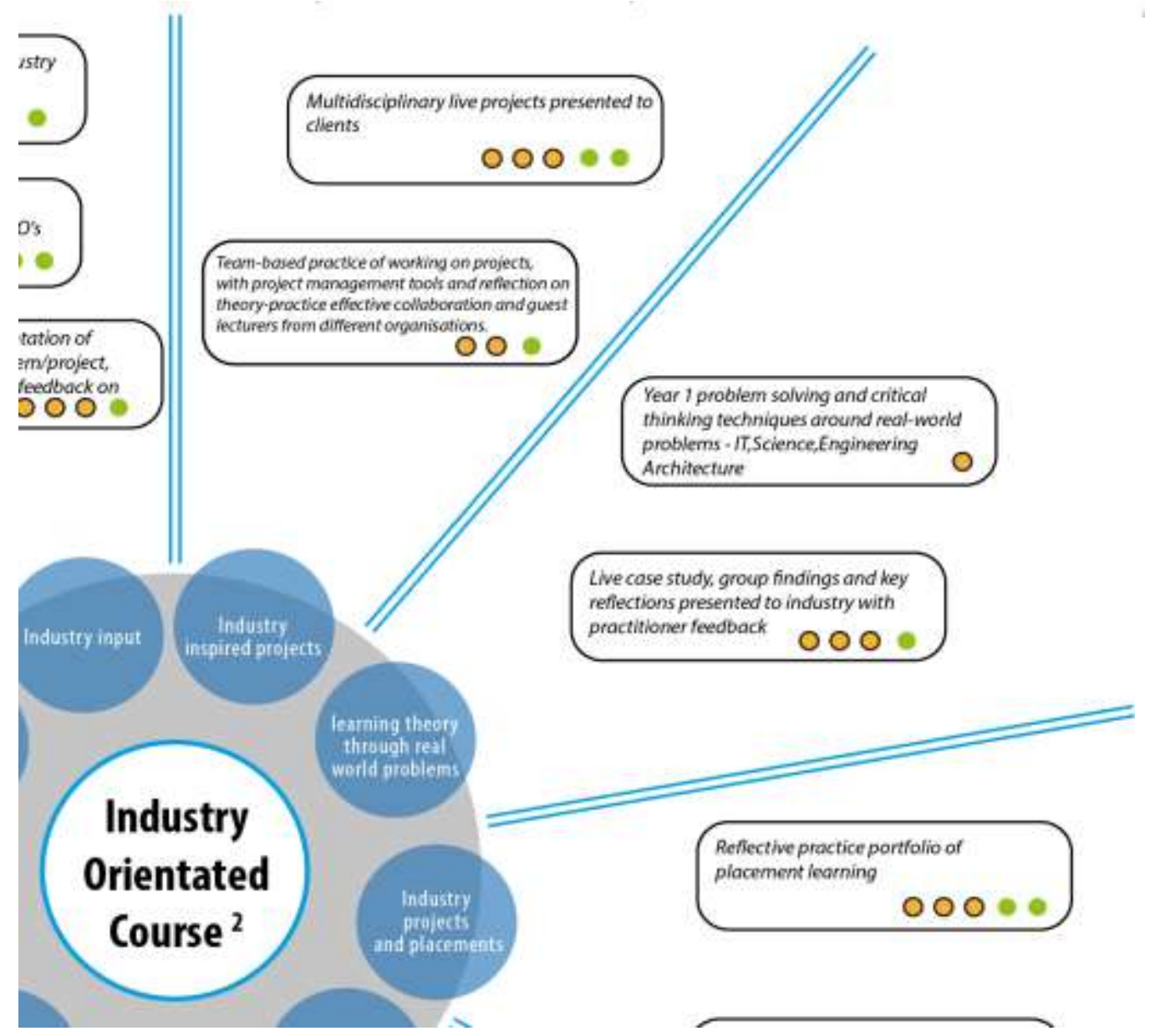

Figure 3: Wedge Section of WIL: Enhancing Employ-ability Outcomes Infographic

The scholarly approach to curriculum renewal, supported by dynamic resources, visually reinforce the narrative of why, what and how to change curriculum. It aligns with current thinking that a whole-of-course scaffolding of WIL curricula is essential to maximise enhanced employability and employment outcomes (Kaider et al., 2017). This harks to the need to shift intentional integration where students have multiple opportunities within a course to work to learn and learn to work (Orrell, 2011).

The WIL Convergence Curriculum Framework (Young, 2016) titled, 'WIL: Enhancing Employability Outcomes' (see Figure 4 below), became an instrumental framework to help academics believe in the value of industry-oriented integrated approaches to delivering WIL elements in curricula. It functioned as a: multi-dimensional, interdependent representation of authentic and proximal assessment definitions; Faculty-centric assessment exemplar resource; and an industry-oriented whole-of-course approach to curriculum. The employability framework provides WIL curriculum standards for mapping, review and renewal of whole-of-course approaches to WIL curriculum design. 


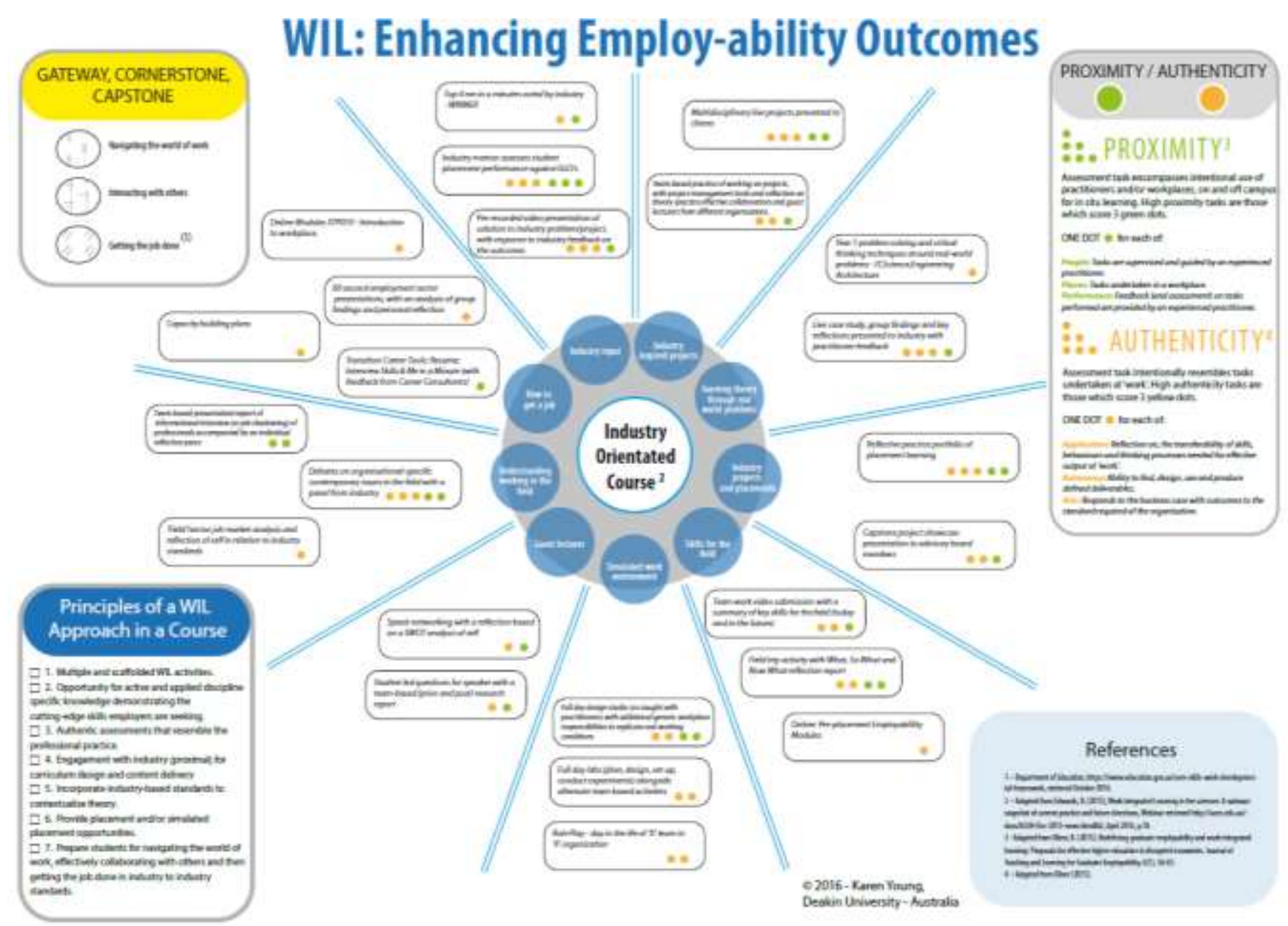

Figure 4: WIL Convergence Curriculum Framework

The infographic (see page 232 for a larger view) intentionally presents the simultaneous interaction of the structure (course) and minutia (assessment) of curricula. It is most useful as a conceptual framework for building the capacity of course teams to re-view their understandings about how curricula can enhance employability by preparing students for the world of work. The examples provide academics who lack current industry experience with ideas for non-traditional assessments. The three tested frameworks provide a scholarly approach to WIL needed for a wide-scale adoption of both WIL practice and WIL scholarship (Reeders, 2000). Together, the frameworks provide a starting point to imagine industryoriented learning activities linked to assessment ideas. Using these converged frameworks for building intentional activities, that apply discipline-specific 'in-context' skills and knowledge performed at a graduate level was crucial to meeting industry requirements and to enhancing student employability outcomes. This approach was influenced by a study that prompts the sector for a reduction in the avoidance of WIL curricula in mainstream curricula (Smith, 2016, p. 347).

The central WIL team understood, like Mcllveen et al. (2008), that there was a need to frame WIL as both an accessible and a legitimate aspect of disciplinary scholarship. WIL had to be presented and conceived in a way that enabled it to be placed within mainstream curricula, not as a bolt on, and not an extra-curricular activity. The following section discusses the decisions, processes and outcomes relating to the 'hunting' and 'gathering' of WIL champions as the early adopters and thus, first enablers for developing and effecting change in curricula through a WIL-lens for the purposes of enhancing graduate employability. 


\section{Discussion and findings}

Findings from this project reveal that the deliberate decision to build the capacity and capability of Course Directors and WIL champions as the first frontier for continuing course enhancement through a WIL-lens proved useful. In particular, the project identified the type of support WIL champions and WIL followers require in order to effect the types of curriculum changes needed in the Faculty to shift the focus in curricula to include scaffolded WIL activities. The key items reported by respondents related mainly to a raised awareness of WIL ideas and strategies and a deeper understanding of what WIL is. One Course Director illustrated this in their survey response with the realisation that WIL was: the embedding and scaffolding of employability skills from year 1-3 in two courses in our school.

During the capacity building processes from 2015 to the end of 2016, there were three key challenges identified as obstacles for enabling change in effective WIL-focused curricula change. First, academics reported that their understanding of WIL and its purposes was still unclear. A seminal report on WIL by Patrick et al. (2008, p. v5), states that WIL is an umbrella term for a range of approaches and strategies that integrate theory with the practice of work within a purposefully designed curriculum. Despite the definition being useful when WIL education emerged in Australian Higher Education, the nebulous concept did not appear to assist academics in the Faculty. The insight gained was that a Faculty-centric shared understanding of WIL was going to be fundamental to WIL curriculum renewal.

The flow on effect, and thus the second change-management challenge, related to behavioural aspects around academic workload and recognition. WIL capacity and capability building initiatives revealed that academics were behaving as the research indicated - that STEM academics tend to focus on their discipline-specific research (and content teaching), and prioritise rigorous discipline-specific research output (National Research Council, 2003, p. 2). Without a significant WIL recognition and reward process in place, the onus was on convincing unit chairs in non-placement units, to see the value in, and the role they had to play, in incorporating elements of a WIL approach into their units. The insight gained was to connect WIL-focused activities to the learning needed to satisfy the overarching course learning outcomes.

The third significant challenge was that WIL was a 'hidden curriculum' in the courses investigated. As part of the ACDS Lighthouse project, the Faculty reported that it has had a longstanding curriculum initiative for all undergraduate courses to provide students with a WIL opportunity. Currently, these student offerings are not coordinated, scaffolded or organised to any large extent in ways that allow students to evidence growth in their learning about work, skills and employment (Campbell, 2016, p. 40). This project identified that there are elements of WIL that already exist but are not fully realised within a WIL framework. The insight gained here was to plan for changes to the documentation and signposting of all WIL focused courserelated materials.

There were therefore, three key areas that needed to be addressed: limited shared understandings of WIL; reluctance by some academics to take on new ways of teaching and assessing in STEM to fit with authentic WIL frameworks; and shifting WIL learning activities from the hidden to the formal curriculum.

\section{Shared understanding}

Improving the understanding of authentic assessment (given that authenticity is the cornerstone of WIL education) was the first project challenge. The Faculty identified that the term authentic, like WIL, was also nebulous for traditional academics. Feedback from academics during the projects revealed the need to unpack the purpose of authentic assessment in a work integrated learning (WIL) framework - that being to provide an opportunity for students to acquire relevant employability skills that link theory to practice in work-related contexts. 
Deakin University has defined WIL as any learning task or experience that is authentic (resembling what is expected of new graduates) and/or proximal (in relation to physical or digital workplaces, and professionals), for the development of graduate employability and career transition (Deakin University, 2017). While the University is geared to improving employability for all students through WIL, each faculty has its own unique approach and thus provides contextualised learning that responds to, and is responsive to, discipline-specific pedagogies and scholarship, as well as the satellite industries underpinning an industryoriented approach to enhancing employability through WIL.

\section{Authentic curricula}

The preferred definition used to guide WIL teaching and assessment practice in the Faculty is from Gulikers, Bastiaens, and Kirschner (2004) who argue that the degree of fidelity of the task and the conditions in which the performance takes place is critical. They define authentic assessment as an assessment requiring students to use the same competencies, or combinations of knowledge, skills, and attitudes that they need to apply in the criterion situation in professional life (Gulikers et al., 2004, p. 69). The authentic assessment should have relevance to both the student's learning of their discipline knowledge and also the acquisition of the relevant complimentary graduate capacities. A deliverable of a current research project within the Faculty is the further refinement and consensus on what authentic assessment within a WIL framework means and how it should be measured in STEM disciplines. This points to the slow but significant way in which change management tends to occur.

It was necessary for the Faculty to adapt a definition to a Faculty-oriented and STEM-centric definition. The project team chose to base the definition on the Deakin University definition given that it used the authenticity/proximity measures that were important in our framework. In STEM, WIL is assigned as a vehicle for developing students' work readiness skills to industry standards and enhancing employability (Edwards et al., 2015, p. 6). The origins of this type of dialogue are found prior to the turn of this century through the push in Higher Education for quality assurance measures relating to the outcomes and capabilities of graduates (Leathwood \& Phillips, 2000; Smith, 2016). Required by successive federal governments since 1998, most HE institutions identify a list of expected learning outcomes (historically often referred to as 'graduate attributes'). In addition, many programs' accrediting professional bodies also specify a list of graduate outcomes that accredited undergraduate programs must incorporate. For over a decade now, WIL has been designated in HE as a learning approach for the development of interpreted and contextualised graduate learning outcomes, providing the benefit of authentic exposure to the expectations and unstructured nature of the typical workplace (Crebert, Bates, Bell, Patrick, \& Cragnolini, 2004; Hart \& Stone, 2002).

\section{Moving from the hidden to the formal curriculum}

Ideas on how to improve WIL activity were approached by presenting arguments from the literature on the value of placement alternatives, as well as by providing examples of assessments that demonstrated learning from authentic activity The principles from Orrell (2011) relating to 'learn to work' concepts were critical. On-campus WIL activities, simulated settings and learning scenarios that resemble real-world practices, such as industry-projects and field trips, to name a few (Billet, 2010), were explained as useful alternatives and preparations for placement-WIL. Campbell (2017) developed the WIL definition for the Faculty which, since 2015, evolved slightly to the final definition used here to ensure that it aligned with the Faculty's strategic focus for increasing the employability and employment outcomes of STEM graduates:

WIL describes the intentional learning activities that expose students to authentic and proximal opportunities to help develop the transferable skills for employment, 
further education and active participation in their community. WIL activities should seek to provide students with the opportunity to learn how to apply specific discipline knowledge, skills \& practice in the workplaces of the future (p. 1).

The time dedicated to perfecting the Faculty-centric WIL definitions, and the broadening of awareness of non-placement WIL, was a direct result of the resistance some academics had towards implementing WIL during the initial phases of the WIL strategy. However, this process contributed significantly to the capacity and capability building of the academics. This enabled the Faculty to enliven the WIL vision and thus enhance the success of current and subsequent WIL projects.

Consequently, in 2016, the Faculty chapter of the Lighthouse Project focused on the task of good WIL hunting and capacity building and has since seen significant cultural shifts. As part of the evaluation undertaken at the close of the Lighthouse project (end of 2016), Course Directors from one of the Schools in the Faculty were asked a number of open-ended, forwardlooking questions about WIL. Participants reported that they learned three key aspects through their participation in the WIL Lighthouse project:

1. WIL encompasses a spectrum of learning activities, not just industry placements;

2. Many learning activities currently undertaken by students can already be considered as having WIL aspects and/or can be adapted in a straightforward manner to do so; and,

3. There is a need for a common understanding of the meaning of WIL.

To determine whether the intended capacity building during the Lighthouse Projects would enable the scalable and sustainable approach to WIL in the Faculty, Course Directors were asked how they would promote WIL and encourage others to develop their understanding and implementation of WIL. The following suggestions covered the range from generic to specific:

- General encouragement for academic staff to develop WIL in courses as a means to improve graduate employability;

- Providing information to academic staff explaining the different types of WIL and how these can be integrated into/across courses coherently;

- Identifying professional development mechanisms for engaging course teams in WIL enhancement, such as course team meetings and workshops.

The Lighthouse Project research findings indicate that while individual academics were indeed working on specific curriculum elements for action to strengthen and highlight WIL aspects, more explicit and intentional, purposeful and measured scaffolding of the curriculum design was going to be required to meet the markers for evidence of enhanced employability curriculum initiatives.

In summary, the research, review, adaptation and then layering of the three frameworks that resulted in the creation of a fourth framework has helped the uptake of WIL within and across the Faculty. This is evidenced by all Course Directors (in three of the four Schools) approving the inclusion of a compulsory first year level introductory WIL unit for students to complete prior to enrolling in a core placement unit. This means that WIL is now core at both the entry and penultimate years of study for the majority of the undergraduate courses (with the fourth School now planning for this School-wide course change to take effect in 2018) in the Faculty. The course changes thus provide scope for sequenced and scaffolded on-campus WIL to facilitate intentional, scalable and sustainable gateway, cornerstone and capstone WIL.

Furthermore, the bedrock of the Faculty's sustainable and scalable approach to embedding intentional WIL curricula, enhancing graduate employability opportunities and improving employment outcomes will take effect in the last half of the strategic plan (2017-2019) through a persistent and even sharper focus on the following curriculum oriented goals: 
- The first-year introductory WIL unit - core in every Faculty undergraduate course - to become a pre-requisite to a core second year unit (as opposed to a later offered placement unit) to ensure WIL awareness occurs earlier in a course sequence.

- Development of WIL-specific learning outcomes (Sin \& Amaral, 2017, p.105).

- Further revision (once tested and evaluated) to the Faculty definition of authentic assessment through a WIL framework.

- Use of an authentic and proximal assessment criterion and standards for measuring 'real-world' applications of knowledge and skills.

- Embedding of career education from first year, not as 'bolt on' initiatives, but constructively aligned to the course learning outcomes.

- Case-study exploration of traditional (STEM) and non-traditional (non-STEM) professional identities for graduates to navigate how to develop, use and discuss their transferable skills to be productive and employable in STEM industries and beyond.

- Signposting within the formal curricula of learning related to future workplace requirements.

- Ensuring programs provide opportunities, early in a course, for students to develop skill sets for 'getting the work done' not just via placement-WIL, but also via on-campus WIL activities.

- Opportunities for all students to have a placement experience as part of their course.

- Multiple and scaffolded opportunities for industry-oriented learning experiences.

- Consideration of how industry-experts might be best involved in teaching and assessment delivery so that in-class learning is not devoid of in-context learning.

- Reflective practice as a core requirement of a WIL assessment.

- Replication of the course-wide capacity building approach to every undergraduate course in the Faculty.

- Refinement of documentation processes and policy to improve the quality of WIL curriculum renewal (i.e. unit guide, major course review and performance review processes).

\section{Future directions}

Ongoing research will provide supporting evidence relating to three measurable aspects of the research projects:

1) Tools and processes that endorse WIL outcomes by aligning authentic and proximal elements of assessment through desk-top audits and course mapping;

2) Evidence of intentional scaffolded and embedded WIL experiences through major course review submissions and out-of-cycle course plans;

3) Longitudinal studies with preparatory studies that consider how to measure the impact of WIL on enhanced employability and employment outcomes of graduates.

Given that both the strategy and related projects are midway through their lifecycle, further exploration of academic perceptions of WIL within the Faculty will continue. In particular, it will be interesting to note if there are indications of shifts, not just in the shared understandings of WIL, but also of the value of WIL and the way in which WIL will be fit-for-purpose to each course context. Desktop audits of assessment and curricula changes that result from the projects are also still underway.

The intention is to measure employment outcomes via a student survey instrument derived from the employability modelling exercise reported in Smith et al. (2014). The model developed was the result of a large-scale investigation into the impact of WIL on undergraduate employability in an Australian context. The principal model reported included six dimensions of work readiness (Smith et al., 2014, p. 29). As a pragmatic/practical measure of graduate employment, the results of the national Graduate Outcomes Survey (GOS) will be significant. These data are useful for program reporting requirements, but they may also be 
used as a dependant variable, for which the identity and influence of as many independent variables as possible are sought. A key independent variable is a student's participation in WIL activities, or not. Based on the related literature, other potentially important independent variables include prior academic performance, discipline area, gender, age, disability status, nationality and socio-economic status. These data are directly available in, or can be derived from, individual student information records held by the university, and can be matched to the corresponding student responses provided to the GOS.

\section{Conclusion}

Developing a refined Faculty-centric definition of WIL, which created a shared understanding of WIL, has been fundamental to the step-change occurring within the Faculty. The discussions created an opportunity for including WIL-focused curricula into traditional STEM curricula. The process built the capacity of Course Directors to better understand the different forms of WIL available to best deliver critical discipline specific skills and knowledge within an employability framework. The exploration of the possible STEM-centric versions and dimensions of WIL activity revealed the 'hidden WIL' aspects of the curriculum, allowing these activities to be more prominent and identifiable. As a result, the construction of the WIL Convergence Curriculum Framework provided a slow, subtle yet salient approach for enabling the re-design of whole-of-course embedded WIL. The scholarly approach to defining WIL and curriculum renewal, supported by dynamic resources visually reinforce the narrative of the 'why, what and how' to enable step-change in curriculum development. But overall, the deliberate choice to build the capacity of a Faculty-based WIL team of experts, and then Course Directors as the first frontier for enabling a sustainable and scalable Faculty-centric and course-wide approach, has been the single most valuable approach taken in the first two years of the five year operational plan.

In particular, the findings from the Science Lighthouse project continue to be instrumental for driving and effecting curriculum change. A number of suggestions from the online survey that participants completed highlight the means through which we will continue to effect and enable change in the understanding and practice of WIL:

i) continuing to be overt in public forums regarding the promotion of the value and importance of WIL;

ii) course mapping of authentic assessments (as opposed to WIL curriculum more generally) for identifying opportunities to increase intentional WIL learning and enhance hidden WIL curriculum;

iii) bringing in 'WIL experts', as visitors or permanent members, to course teams, school meetings, etc.; and,

iv) running more WIL events for School learning and teaching leaders with the aim of promoting and developing WIL.

In summary, the above are the future enablers for driving intentional, embedded, scaffolded WIL approaches. The context-rich integrations of career education and theory-practice pedagogies are our greatest promise to improved graduate outcomes in STEM. A whole-ofcourse WIL approach to curriculum design whereby course teams align discipline-specific knowledge and skill acquisition to real world scenarios, thus allowing students to connect their learning to the future world of work is our best opportunity to improve employability skills and employment outcomes.

While it is too early to draw any conclusions about the impact of re-designed curricula on employment outcomes for graduates of the Faculty, the survey data on academics' perceptions of WIL and evidence of core WIL unit inclusions indicate that the change management process, enlivened through grounded research projects, is making an impact on WIL activity at the undergraduate level. The Faculty is confident that the WIL leadership approach to building capacity for curriculum re-design is the most sustainable and scalable catalyst for ensuring a course covers both the 'work to learn and learn to work' domains

Young, K., Palmer, S., \& Campbell, M. (2017). Good WIL hunting: Building capacity for curriculum re-design. Journal of

Teaching and Learning for Graduate Employability, 8(1), 215-232. 
needed for graduates to be more job-ready (Orrell, 2011). The Faculty can now gain further momentum by relying on a wider and growing group of good-WIL champions to be involved in the review, planning and continual renewal of embedded practice-based applications of context-rich discipline-specific knowledge and skill development. 


\section{References}

Abeysekera, I. (2006). Issues relating to designing a Work-Integrated Learning (WIL) program in an undergraduate accounting degree program and its implications for the curriculum. Asia-Pacific Journal of Cooperative Education, 7(1), 7-15. https://ssrn.com/abstract=2326048

Billet, S. (2001). Learning in the workplace: Strategies for effective practice. Crows Nest, NSW, Australia: Allen and Unwin.

Bosco, A. M., \& Ferns, S. (2014). Embedding of authentic assessment in work-integrated learning curriculum. Asia-Pacific Journal of Cooperative Education, 15(4), 281-290.

Campbell, M. (2016). Learning to work, working to learn: Curriculum design and teaching practice for WIL in the Natural and Physical Sciences. In E. Johnson (Ed.), WIL in Science: Leadership for WIL Final Report (pp. 40-43). Sydney: Australian Council of Deans of Science.

Campbell, M. (2017). SEBE WIL Strategy. Victoria: Deakin University.

Crebert, G., Bates, M., Bell, B., Patrick, C. J., \& Cragnolini, V. (2004). Ivory tower to concrete jungle revisited. Journal of Education and Work, 17(1), 47-70. https://doi.org/10.1080/1363908042000174192

Deakin University. (2017). What is work integrated learning? Retrieved from https://blogs.deakin.edu.au/wil/

Department of Education and Training. Core Skills for Work Development Framework (2016). Retrieved from https://www.education.gov.au/core-skills-work-developmentalframework

Edwards, D., Perkins, K., Pearce, J., \& Hong, J. (2015). Work integrated learning in STEM in Australian universities: Final Report. Canberra: Office of Chief Scientist \& Australian Council for Educational Research

Eraut, M., \& Hirsh, W. (2007). The significance of workplace learning for individuals, groups and organisations. Oxford and Cardiff Universities: UK.

Gulikers, J., Bastiaens, T., \& Kirschner, P. (2004). Educational Technology Research and Development (ETR\&D), 52(3): 67-86. https://doi.org/10.1007/BF02504676

Hains-Wesson, R., \& Young, K. (2017). A collaborative autoethnography study to inform the teaching of reflective practice in STEM. Higher Education Research \& Development, 36(2), 297-310. http://dx.doi.org/10.1080/07294360.2016.1196653

Hart, G., \& Stone, T. (2002). Conversations with students: The outcomes of focus groups with QUT students. Paper presented at the Quality Conversations - Higher Education Research and Development Society of Australasia Conference, Perth.

Henderson, C., Beach, A., \& Finkelstein, N. (2011). Facilitating change in undergraduate STEM instructional practices: An analytic review of the literature. Journal of Research in Science Teaching, 48(8), 952-984. https://doi.org/10.1002/tea.20439

Johnson, E. (2016). ACDS WIL in Science: Leadership for WIL Final Report. Sydney: Australian Council of Deans of Science. Retrieved from http://www.chiefscientist.gov.au/wp-content/uploads/WIL-in-Science-project-report2016-final-publication-post-review.pdf

Kaider, F., Hains-Wesson, R., \& Young, K. (2017). Practical typology of authentic workintegrated learning activities and assessments. Asia-Pacific Journal of Cooperative Education, Special Issue, (18)2, 153-165.

Leathwood, C., \& Phillips, D. (2000). Developing curriculum evaluation research in higher education: Process, politics and practicalities. Higher Education, 40(3), 313-330. https://doi.org/10.1023/A:1004183527173

Mcllveen, P., Brooks, S., Lichtenberg, A., Smith, M., Torjul, P., \& Tyler, J. (2008). Career development learning \& work-integrated learning in Australian higher education: A discussion paper. Paper presented at the National Symposium on Career Development Learning: Maximising the Contribution of Work-integrated Learning (WIL) to the Student Experience, Melbourne. https://doi.org/10.1007/978-90-481-3937-8 9 
National Research Council. (2003). Improving undergraduate instruction in science, technology, engineering, and mathematics: Report of a workshop. Washington, D.C.: National Academies Press. https://doi.org/10.17226/10711

Norton, A., \& Cakitaki, B. (2016). Mapping Australian higher education 2016. Melbourne: Grattan Institute.

Oliver, B. (2015). Redefining graduate employability and work-integrated learning: Proposals for effective higher education in disrupted economies. Journal of Teaching and Learning for Graduate Employability, 6(1), 56-65. http://dx.doi.org/10.21153/itlge2015vol6no1art573

Orrell, J. (2011). Good practice report: Work-integrated learning. NSW: Australian Learning \& Teaching Council.

Palmer, S., Tolson, M., Young, K., \& Campbell, M. (2015). The relationship between engineering bachelor qualifications and occupational status in Australia. Australasian Journal of Engineering Education, 20(2), 103-112. https://doi.org/10.1080/22054952.2015.1092666

Patrick, C.J., Fallon, W., Campbell, M., Devenish, I., Kay, J., Lawson, J., Russell, L., Tayebjee, F. \& Cretchley, P., (2014). Leading WIL: A distributed leadership approach to enhance work integrated learning: Final Report 2014. NSW: Department of Education, Office for Learning and Teaching.

Patrick, C.J., Peach, D., Pocknee, C., Webb, F., Fletcher, M., \& Pretto, G. (2008). The WIL (Work Integrated Learning) report: A national scoping study. Queensland University of Technology.

Poppins, P., \& Singh, M. (2005). Work integrated learning in information technology education. In T. Weert \& A. Tatnell (Eds), Information and communication technologies and real life learning: New education for the knowledge society, (pp.223-230). Boston: Springer. https://doi.org/10.1007/0-387-25997-X 25

Reeders, E. (2000). Scholarly practice in work-based learning: Fitting the glass slipper. Higher Education Research \& Development, 19(2), 205-220. http://dx.doi.org/10.1080/072943600445655

Rowe, A., Winchester-Seeto, T., \& Mackaway, J. (2012). That's not really WIL!-building a typology of WIL and related activities. Paper presented at the 2012 Australian Collaborative Education Network National Conference.

Sin, C., \& Amaral, A. (2017). Academics' and employers' perceptions about responsibilities for employability and their initiatives towards its development. Higher Education, 73(1), 97-111. https://doi.org/10.1007/s10734-016-0007-y

Smith, C. D. (2016). The emergence and development of Work-Integrated Learning (WIL): Implications for assessment, quality and quality assurance in higher education. In C. $\mathrm{Ng}$, B. Fox \& M. Nakano (Eds.), Reforming learning and teaching in Asia-Pacific universities, (pp. 337-364). The Netherlands: Springer. https://doi.org/10.1007/978-98110-0431-5 16

Smith, C., Ferns, S., Russell, L., \& Cretchley, P. (2014). The impact of work integrated learning on student work-readiness. NSW: Department of Education, Office for Learning and Teaching.

Tolson, M., \& Young, K. (2016). SEBE Model of WIL. In M. Whelan \& L. Johnson, Roundtable: WIL in Science. Paper presented at the WIL 2020: Pushing the boundaries - Proceedings of the 2016 ACEN National Conference, Springvale South, Australia.

Universities Australia, Australian Chamber of Commerce Industry, Australian Industry Group, Business Council of Australia, \& Australian Collaborative Education Network. (2015). National strategy on work integrated learning in university education.

Willems, J., Young, K., Cardilini, A., \& Teychenne, S. (2016). WIL-fully flipping online: A novel pedagogical approach in STEM. Paper presented at the 33rd International Conference of Innovation, Practice and Research in the Use of Educational Technologies in Tertiary Education, Adelaide, Australia.

Yorke, M. (2006). Employability in higher education: What it is-what it is not (Vol. 1). Higher Education Academy, York. 
Young, K. (2016). WIL Convergence Curriculum Framework. SEBE. Deakin University. Victoria, Australia.

Young, K., Cardilini, A., Willems, \& Teychenne, S. (2016). STP010/710 - fully flipped. Paper presented at the Deakin Learning Futures, Deakin University, Melbourne, Australia.

Young, K., Palmer, S., Tolson, M., \& Campbell, M. (2016). Distributed leadership model: Enabling faculty-wide enhancement of scaffolded WIL. Paper presented at the WIL 2020: Pushing the boundaries - Proceedings of the 2016 ACEN National Conference, Springvale South, Australia. 


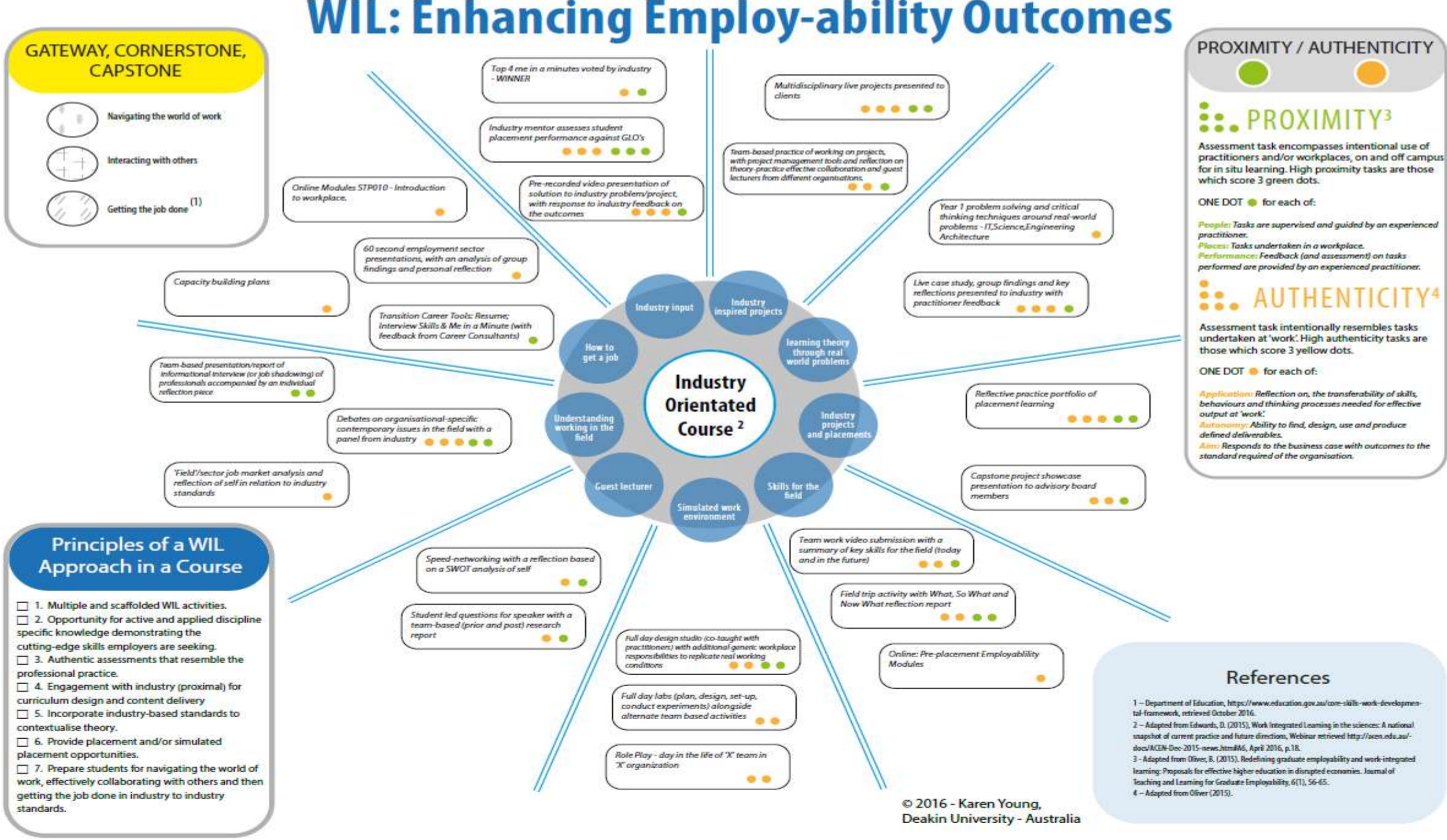

